\title{
The variety of primary care
}

\section{Glenn Duns}

\section{Nothing is pleasant that is not spiced with variety.}

\section{- Francis Bacon ${ }^{1}$}

In this issue of Australian Journal of General Practice (AJGP) on haematology and biochemistry, we present a collection of articles that demonstrate the breadth of clinical challenges faced by general practitioners (GPs) working within primary care. Professional and research articles explore the new Australian guidelines on familial hypercholesterolaemia, ${ }^{2,3}$ while articles on myeloproliferative neoplasms ${ }^{4}$ and glycated haemoglobin ${ }^{5}$ provide clinical guidance.

Early in my career, the importance of primary care became apparent. Family medicine mentors at McGill University and expert authors ${ }^{6}$ taught that primary care is a central facet of the healthcare system, and part of a humanistic tradition that can be traced back to the Declaration of Alma-Ata and the Universal Declaration of Human Rights. ${ }^{7}$ It was also clear that health services reforms that place primary care at the centre will require government policy support. ${ }^{8}$

The value of primary care is well established, but there is an important difference between seeing the value of your work and feeling valued. Although multifactorial, I believe that a key component is related to the paradox of primary care: namely, that when compared with care from non-primary care specialists, or with systems dominated by non-primary care specialists, research has shown that primary care is associated with '(1) apparently poorer quality care for individual diseases yet (2) similar functional health status at lower cost for people with chronic disease, and (3) better quality, better health, greater equity, and lower cost for whole people and populations'. ${ }^{9}$
Keeping in mind that the standard of care used as a measurement is often based on guidelines that are developed outside of the primary care setting, there remains the perception that non-primary care specialists can provide a higher standard of care for individual diseases within their specialty. However, it is the ability of primary care specialists to manage all aspects of a patient's health that is associated with critically important positive outcomes on an individual and societal basis.

I think that as a group we need to continue to actively promote the value of, and our ability to provide, whole-patient care, while recognising that at the level of the individual practitioner there will be different methods to address the challenges of practising primary care. Practitioners may choose to develop an area of specific interest; ${ }^{10}$ some might pursue research to develop guidelines that are specific to the primary care context, others will continue to hone their skills in whole-patient care, while others will pursue a combination of interests within primary care. Ultimately, I believe that a vision of general practice as being diverse, with people of varied interests and backgrounds working towards a common goal of achieving the best outcomes and highest standard of care for individuals and society, is something that everyone can support.

This is my final issue as I wrap up an eight-year shift at AJGP, and it comes in the context of a marked increase in both the quantity and complexity of clinical work, ${ }^{11}$ which provides another example of the challenges faced in primary care. I started the role of Medical Editor in 2013 soon after completing a Master of Public Health degree at the University of Melbourne. I found the additional knowledge, skills and understanding gained from this degree to be helpful in contributing to high-quality patient care, and this has informed my role as editor with the AJGP.

As I look forward to new challenges, I'd like to thank The Royal Australian College of General Practitioners, fellow editors and the readership for allowing this invaluable experience. I wish everyone continued success and enjoyment in their essential roles of supporting and providing the highest quality patient care.

\section{Author}

Glenn Duns MDCM, FRACGP, MPH; Medical Editor, Australian Journal of General Practice; General Practitioner, Melbourne, Vic

\section{References}

1. Brainy quotes. Francis Bacon quotes. Mercer Island, WA: BrainyQuote, 2021. Available at www. brainyquote.com/quotes/francis_bacon_149872 [Accessed 9 August 2021].

2. Brett T, Radford J, Heal C, et al. Implications of new clinical practice guidance on familial hypercholesterolaemia for Australian general practitioners. Aust J Gen Pract 2021;50(9):616-21.

3. Bulsara C, Brett T, Radford J, et al. Awareness of familial hypercholesterolaemia in Australian primary care: A qualitative descriptive study. Aust J Gen Pract 2021;50(9):634-40.

4. Lin R, Tan YL. Myeloproliferative neoplasms: Classifications and an approach to diagnosis. Aust J Gen Pract 2021;50(9):622-27.

5. Wang M, Hng T-M. HbA1c: More than just a number. Aust J Gen Pract 2021;50(9):628-32.

6. Starfield B. Primary care: Balancing health needs, services and technology. New York, NY: Oxford University Press, 1998.

7. Rawaf S, De Maeseneer J, Starfield B. From AlmaAta to Almaty: A new start for primary health care. Lancet 2008;372(9647):1365-67. doi: 10.1016/ S0140-6736(08)61524-X

8. Starfield B. Politics, primary healthcare and health: Was Virchow right? J Epidemiol Community Health 2011;65(8):653-55. doi: 10.1136/ jech.2009.102780.

9. Stange KC, Ferrer RL. The paradox of primary care. Ann Fam Med 2009;7(4):293-99. doi: 10.1370/afm.1023.

10. The Royal Australian College of General Practitioners. Specific Interests groups. East Melbourne, Vic: RACGP, 2021. Available at www. racgp.org.au/the-racgp/faculties/specific-interests/ interest-groups [Accessed 9 August 2021].

11. Woodley M. Public hospitals 'completely overrun' due to COVID delays. newsGP. 17 May 2021. Available at www1.racgp.org.au/newsgp/ professional/public-hospitals-completely-overrundue-to-covid-d [Accessed 9 August 2021]. 